\title{
Chemothermal Therapy for Localized Heating and Ablation of Tumor
}

\author{
Zhong-Shan Deng, $\mathbf{P h D}^{\mathbf{1}}$ and Jing Liu, $\mathbf{P h D}^{\mathbf{1 , 2 *}}$ \\ ${ }^{1}$ Key Lab of Cryogenics and Beijing Key Lab of CryoBiomedical Engineering, \\ Technical Institute of Physics and Chemistry, Chinese Academy of Sciences, \\ Beijing 100190, China \\ ${ }^{2}$ Department of Biomedical Engineering, School of Medicine, Tsinghua University, \\ Beijing 100084, China
}

Submitted September 2012. Accepted for publication June 2013.

\begin{abstract}
Chemothermal therapy is a new hyperthermia treatment on tumor using heat released from exothermic chemical reaction between the injected reactants and the diseased tissues. With the highly minimally invasive feature and localized heating performance, this method is expected to overcome the ubiquitous shortcomings encountered by many existing hyperthermia approaches in ablating irregular tumor. This review provides a relatively comprehensive review on the latest advancements and state of the art in chemothermal therapy. The basic principles and features of two typical chemothermal ablation strategies (acid-base neutralization-reaction-enabled thermal ablation and alkali-metal-enabled thermal/chemical ablation) are illustrated. The prospects and possible challenges facing chemothermal ablation are analyzed. The chemothermal therapy is expected to open many clinical possibilities for precise tumor treatment in a minimally invasive way.
\end{abstract}

Keywords: tumor hyperthermia, chemothermal therapy, conformable ablation, exothermic chemical reaction, localized heating, minimally invasive therapy, injectable medium

\section{INTRODUCTION}

Hyperthermia has long been an important tumor treatment modality, ranked only after radiotherapy and chemotherapy [1]. Different from the routinely adopted radiotherapy and chemotherapy, this method only changes the temperature of diseased tissues and induces minor side effect which wins its fame as a "Green Therapy" [2]. Up to now, a wide variety of hyperthermia approaches based on different heat generation principles have been established, such as microwave [3-5], high intensity focused ultrasound [6, 7], radiofrequency [8, 9], magnetic fluids [10-13], laser [14-16], and hot medium [17], etc.

*Corresponding author: Jing Liu, Key Lab of Cryogenics and Beijing Key Lab of CryoBiomedical Engineering, Technical Institute of Physics and Chemistry, Chinese Academy of Sciences, Beijing 100190, China. Phone: +86-10-82543765. Fax: +86-10-82543767. E-mail: jliubme@tsinghua.edu.cn. Other author: zsdeng@mail.ipc.ac.cn. 
However, major drawbacks in these approaches are in the cost and inevitable thermal damage to the surrounding healthy tissues along the path that heat energy is transmitted from outside to the target tumor embedded inside the human body. For a widespread clinical application of hyperthermia, two important but extremely difficult issues are (a) generation of a high enough temperature increase should be confined only within the target region (tumors) and leaving all the surrounding healthy tissues intact, and (b) temperature detection and control within as well as outside the target region should be easily available $[18,19]$. Due to the irregular shapes of tumors, there is still a long way for the current hyperthermia techniques to satisfactorily address the above two issues. There is a great need to establish a highly localized, economic, safe, efficient and powerful heating strategy for thermal ablation of tumor.

In view of all these important issues, efforts were made by the authors and other groups in recent years in exploratory researches on methodology of hyperthermia, particularly a method which can generate high enough heat energy only in the target tissue. A promising solution is heating by exothermic chemical reaction [20]. It is well known that many chemical reactions release heat. Therefore, by choosing appropriate exothermic chemical reactants and injecting them into the target tumor, the corresponding exothermic chemical reaction could release enough heat to thermally ablate the tumor tissue [21,22]. The ingredient in tumor tissue such as water can also serve as the reactant for such purpose. Only the reactant such as liquid $\mathrm{NaK}$ is to be injected into the tumor tissue, which would result in exothermic reaction when reacting with water in the tissue, and would thermally ablate the tumor [23]. It should be pointed out that the reaction also generates a caustic environment with a higher $\mathrm{pH}$ than normal tissue. However, due to the fact that only extremely small amount of liquid $\mathrm{NaK}$ is needed for this case, the $\mathrm{pH}$ value in the tissues surrounding the injection site will be not too high after treatment. Based on the above consideration, we proposed a series of exothermic-reaction-based hyperthermia methods with high intensity heat release effect on the target tissue, in which the residual reactants and resultants can be easily absorbed by human body [21-23]. Among them, the methods of acid-base neutralization reaction [22] and alkali-metal thermal/chemical ablation [23] are two examples. These methods can ensure that high intensity heat is only released at the target tissue site but not the surrounding healthy tissues.

The exothermic-reaction-based hyperthermia can be defined as chemothermal therapy or ablation. This concept was first proposed by the authors' group [21-24], and subsequently, similar works were reported by other researchers [25-28]. Compared with most of the existing hyperthermia strategies, the heating involved in chemothermal therapy is highly localized which will remarkably reduce the thermal damage and mechanical trauma to the surrounding healthy tissues. This method opens the clinical possibilities for a low cost but highly efficient tumor treatment that is minimally invasive by using surgical syringes with diameter smaller than $1 \mathrm{~mm}$.

This review is dedicated to providing an overview on the recent advances and state of the art of two typical chemothermal ablation methods (i.e., acid-base neutralizationreaction-enabled thermal ablation and alkali-metal-enabled thermal/chemical ablation), which might help solve the problems intractable in a conventional hyperthermia modality. The paper is organized as follows. In Section 2, the principle of acid-base 
neutralization-reaction-enabled thermal ablation is introduced, with both experiments and future development trends discussed, which would help provide an insight for further research. Section 3 focuses on the basic principle and anti-tumor effect of alkalimetal-enabled thermal/chemical ablation. Section 4 provides a comparative discussion on the chemothermal therapy and existing hyperthermia approach. Finally, conclusions will be drawn in Section 5.

\section{ACID-BASE NEUTRALIZATIONREACTIONENABLED THERMAL ABLATION}

\subsection{Basic Principle}

Figure 1 shows the principle of acid-base neutralization-reaction-enabled thermal ablation of tumor. The reactants $(\mathrm{NaOH}$ and $\mathrm{HCl})$ at room temperature are directly delivered into the target tissues through a medical syringe (as shown in Figure 1a). A tremendous heat of reaction $(\Delta \mathrm{H}=57.32 \mathrm{~kJ} / \mathrm{mol}[29])$ is released at the target tissue to

(a)

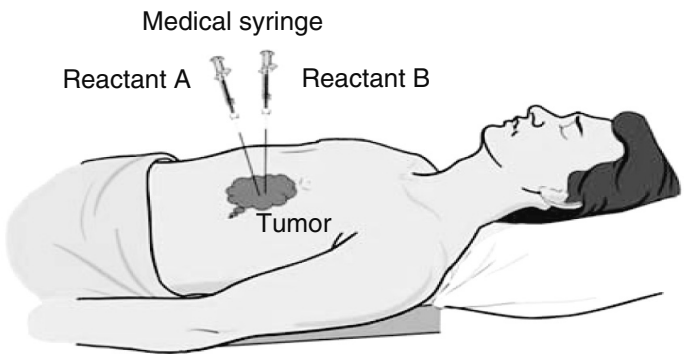

(b)

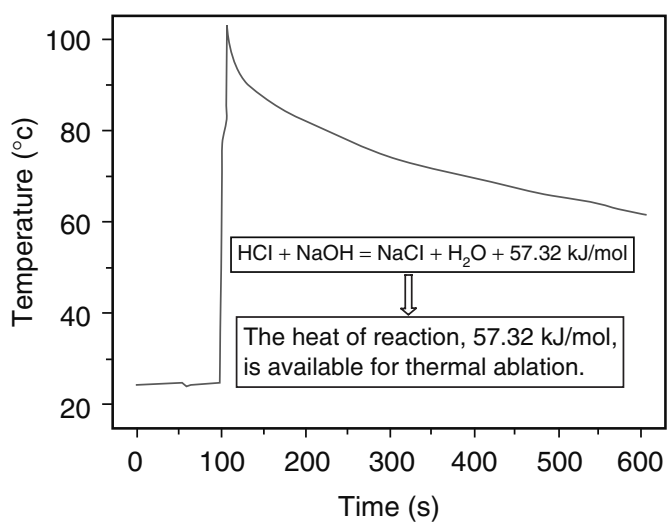

Figure 1. Principle of acid-base neutralization reaction enabled thermal ablation. (a) Schematic for administrating the treatment. (b) The temperature change of solutions during the process of neutralization reaction in which the reactants are $5 \mathrm{~g} 40 \% \mathrm{w} / \mathrm{w}$ sodium hydroxide $(\mathrm{NaOH})$ solution and $5 \mathrm{~g} 37 \% \mathrm{w} / \mathrm{w}$ hydrochloric acid $(\mathrm{HCl})$ [22]. Reproduced with permission. 
elevate its temperature to above tissue's thermally lethal threshold value (usually $45^{\circ} \mathrm{C}$ for tumor tissue [18]) (see Figure $1 \mathrm{~b}$ ). The products $(\mathrm{NaCl}$ and water) are generally nontoxic to the human body. Several possible merits of this therapy are being easy to operate, low cost, highly localized, minimally invasive, simple device design, and possible implementation on an outpatient basis. Such goals have in fact been pursued for many years by oncological clinicians.

Generally, the chemicals for a viable hyperthermia treatment using exothermic chemical reaction must meet the following three requirements: (1) the heat of reaction should be large enough to guarantee a complete thermal damage to the target tissues; (2) the reactants and resultants of the chemical reaction should be safe to the human body; and (3) the reactants can be easily introduced into the target tissues via a minimally invasive approach without causing any thermal, mechanical or chemical adverse effect to the surrounding healthy tissue along the insertion path.

Figure $1 \mathrm{~b}$ depicts the temperature change during the process of a neutralization reaction, in which at $100 \mathrm{~s}$ (time), $5 \mathrm{~g} 40 \% \mathrm{w} / \mathrm{w}$ of sodium hydroxide $(\mathrm{NaOH})$ solution at room temperature was added to $5 \mathrm{~g} 37.5 \% \mathrm{w} / \mathrm{w}$ of hydrochloric acid $(\mathrm{HCl})$, also at room temperature, in an unconfined glass tube. It indicates that the highest solution temperature during the neutralization reaction has even reached $100^{\circ} \mathrm{C}$, far higher than that requested to kill a tumor tissue. In experiment, a boiling phenomenon with vapor generation in the solutions was observed. Clearly, the neutralization reaction of $\mathrm{HCl}$ and $\mathrm{NaOH}$ has the ability in meeting requiremet (1). In addition, requirement (2) is also met since the reaction of $\mathrm{HCl}$ and $\mathrm{NaOH}$ produces $\mathrm{NaCl}$ and $\mathrm{H}_{2} \mathrm{O}$ that are safe to human body. For requirement (3), the injected solutions are at room temperature which does no thermal damage to the surrounding healthy tissue; the medical syringe used to inject the solution is small ( $0.8 \mathrm{~mm}$ in diameter), and the mechanical damage to the healthy tissue along the insertion path is minimal. It should be pointed out that the reactants suitable for acid-base neutralization-reaction-enabled thermal ablation are not limited to $\mathrm{HCl}$ and $\mathrm{NaOH}$, and that any reactant pairs with heat of reaction high enough and no obvious adverse effect can be selected for clinical tumor treatment. Efforts made in this direction would lead to the discovery of a group of useful material candidates.

\subsection{Experiments on Acid-Base Neutralization-Reaction-Enabled Thermal Ablation}

Both in vitro and in vivo experiments were performed in the authors' laboratory to test the feasibility of acid-base neutralization-reaction-enabled thermal ablation, in which in vitro pork tissues and a $2 \mathrm{~kg}$ New Zealand rabbit were selected as experimental subjects, respectively [22]. The temperature sensors used in all experiments were calibrated Ttype copper-constantan thermocouples (24-gauge). To prevent the chemical corrosion by hydrochloric acid, the copper-constantan thermocouple was encapsulated in a capillary glass tube of $1.4 \mathrm{~mm}$ outer diameter and $0.8 \mathrm{~mm}$ inner diameter, in which one end of the capillary tube and the thermocouple head were sintered together.

The typical results for in vitro experiments are depicted in Figure 2 and Figure 3. Considering that the concentrated $\mathrm{HCl}$ and $\mathrm{NaOH}$ will generate heat when diluted separately in the tissues and may contribute to the expected thermal ablation, 
(a)

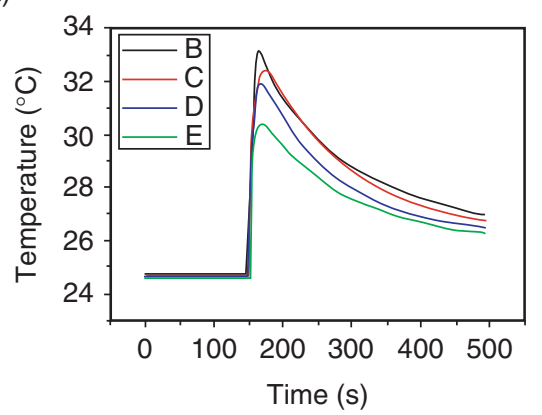

(c)

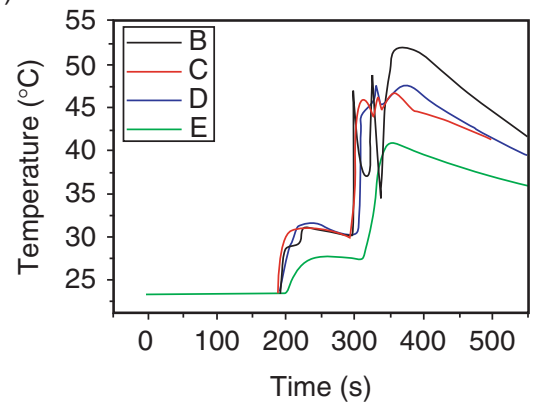

(b)

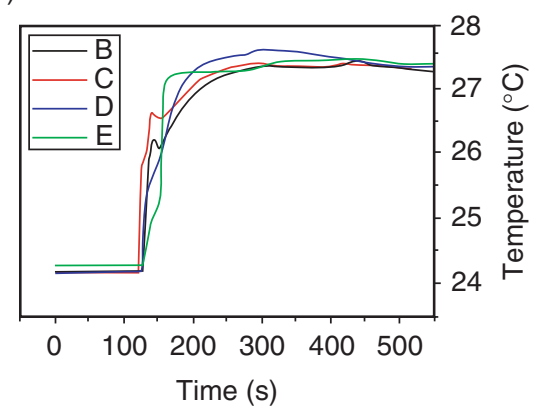

(d)

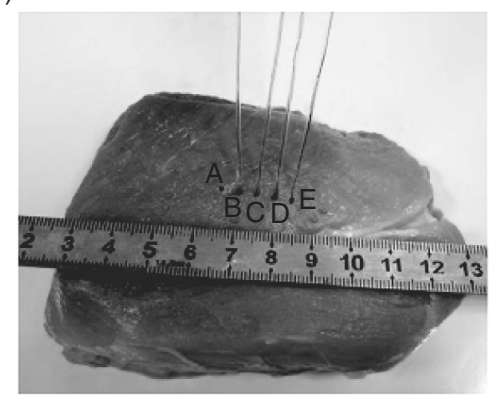

Figure 2. The temperature responses at four locations of in vitro pork tissue. (a) Injection of $5 \mathrm{~g}$ of $37 \% \mathrm{w} / \mathrm{w} \mathrm{HCl}$ into the tissue. (b) Injection of $5 \mathrm{~g}$ of $40 \% \mathrm{w} / \mathrm{w} \mathrm{NaOH}$ into the tissue. (c) Injection of $5 \mathrm{~g}$ of $37 \% \mathrm{w} / \mathrm{w} \mathrm{HCl}$ and $5 \mathrm{~g}$ of $40 \% \mathrm{w} / \mathrm{w} \mathrm{NaOH}$ into the tissue. (d) Photo for one of in vitro tissue experiments in which $\mathrm{A}$ is the injection spot of reactants, and $\mathrm{B}, \mathrm{C}, \mathrm{D}$, and $\mathrm{E}$ are the measuring points of tissue temperature responses with data shown in (a), (b) and (c), respectively. The distance between two adjacent points of $\mathrm{A}, \mathrm{B}, \mathrm{C}, \mathrm{D}$, and $\mathrm{E}$ is $5 \mathrm{~mm}$. The depths of injection and the temperature measurements are all $2 \mathrm{~cm}$ [22]. Reproduced with permission.

experiments were also performed with injection of $\mathrm{HCl}$ or $\mathrm{NaOH}$ only. In Figure 2a, $\mathrm{HCl}$ was injected into the in vitro pork tissue at $150 \mathrm{~s}$. In Figure $2 \mathrm{~b}, \mathrm{NaOH}$ was injected at $120 \mathrm{~s}$. In Figure 2c, $\mathrm{HCl}$ and $\mathrm{NaOH}$ were injected into the tissue at the same spot at $180 \mathrm{~s}$ and $300 \mathrm{~s}$, respectively. In Figure 2d, photo for one of in vitro tissue experiments was illustrated, in which point A refers to the injection spot of reactants, points B, C, D, and $\mathrm{E}$ are the measuring points of tissue temperature responses. The results shown in Figure 2 indicate that the maximum temperature increase is about $8^{\circ} \mathrm{C}$ and $3^{\circ} \mathrm{C}$ for injection of $5 \mathrm{~g}$ of $37 \% \mathrm{w} / \mathrm{w} \mathrm{HCl}$ and $5 \mathrm{~g}$ of $40 \% \mathrm{w} / \mathrm{w} \mathrm{NaOH}$, respectively. Although injection of concentrated $\mathrm{HCl}$ and $\mathrm{NaOH}$ individually does generate heat which resulted in a noticeable temperature increase in the tissue, such heat release is much smaller than that released from the exothermic chemical reaction taking place at $300 \mathrm{~s}$ in Figure 2c, 


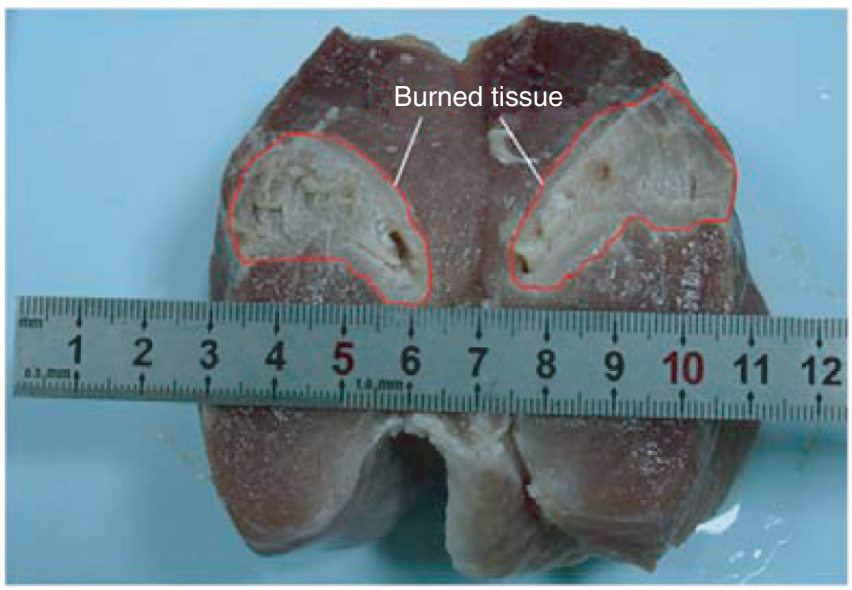

Figure 3. Effect of thermal ablation on in vitro pork tissue, where the reactants are $5 \mathrm{~g}$ of $37 \% \mathrm{w} / \mathrm{w}$ hydrochloric acid and $5 \mathrm{~g}$ of $40 \% \mathrm{w} / \mathrm{w}$ sodium hydroxide solution [22]. Reproduced with permission.

which resulted in about $22^{\circ} \mathrm{C}$ of the maximum temperature increase (from $30^{\circ} \mathrm{C}$ to $52^{\circ} \mathrm{C}$ ) in the target tissue. It is also shown in Figure $2 \mathrm{c}$ that the tissue temperature even at point $\mathrm{D}, 1.5 \mathrm{~cm}$ away from the injection spot, after the chemical reaction occurred is obviously higher than the thermally lethal threshold value for tumor tissue. This result suggests that the present approach may be suitable for thermal ablation. The most attractive feature of this thermal ablation method is that the heat of reaction can be released only in the target region if the dosage and the injection area of solutions were appropriately controlled. It may cause no thermal damage and ultra-small mechanical trauma to the normal tissues along the insertion path, which are however inevitable in many popular hyperthermia procedures such as percutaneous RF ablation. Figure 3 shows the burned tissue area following such experiment, showing that the region of ablated tissue is rather large even only very small amounts of reactants were administered.

To further demonstrate the feasibility of acid-base neutralization-reaction-enabled thermal ablation, in vivo experiments were also performed on live rabbit. During the experiment, $\mathrm{HCl}$ was injected into the rabbit's thigh tissue at $360 \mathrm{~s}$, and $\mathrm{NaOH}$ was injected through the same spot immediately thereafter. It is shown in Figure 4 that the highest temperature in the target tissue reach about $52.5^{\circ} \mathrm{C}$ after the injections, and that even at Point E, $2 \mathrm{~cm}$ away from the injection spot, the temperature increase is large enough to thermally damage the tumor tissue. The primary objective of thermal ablation is to raise the temperature of the diseased tissue to the therapeutic value, typically larger than $45^{\circ} \mathrm{C}$, for several minutes. It is shown in Figure 4 that the temperature of the target tissue is quickly elevated and maintained high for a long period (exceeding 5 minutes even at point E). The current in vivo experiment using rabbit suggested that using the heat released from exothermic chemical reaction to perform hyperthermia is feasible. In 


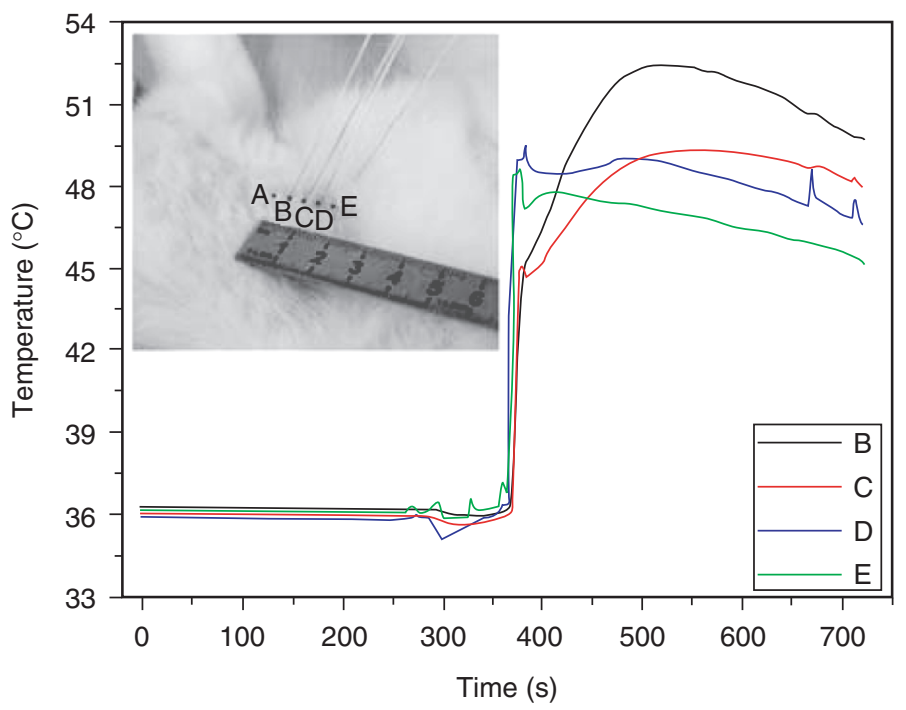

Figure 4. The temperature responses at four locations of in vivo rabbit thigh tissue. $\mathrm{A}$ is the injection spot of reactants; $\mathrm{B}, \mathrm{C}, \mathrm{D}$, and $\mathrm{E}$ are the temperature measuring points. The reactants are $4 \mathrm{~g}$ of $37 \% \mathrm{w} / \mathrm{w} \mathrm{HCl}$ and $4 \mathrm{~g}$ of $40 \% \mathrm{w} / \mathrm{w} \mathrm{NaOH}$. The distance between two adjacent points of $\mathrm{A}, \mathrm{B}, \mathrm{C}, \mathrm{D}$, and $\mathrm{E}$ is $5 \mathrm{~mm}[22]$. Reproduced with permission.

addition, the maximum temperature difference between the measuring points $\mathrm{B}$ and $\mathrm{E}$ is only about $5^{\circ} \mathrm{C}$. It indicates that the temperature increase at the target tissue produced by heat of reaction is very uniform. This is another attractive feature of acid-base neutralization-reaction-enabled thermal ablation.

Besides the experiments on rabbit's thigh, in vivo experiments were also performed on rabbit's liver, and similar results were obtained. As shown in Figure 5, the burned area measures about $2 \mathrm{~cm} \times 3 \mathrm{~cm}$. It again suggests the thermal ablation capability of the present method, and the possibility of high intensity thermal ablation by only injecting a small amount of reactants into the target tissues, a desirable feature in oncology clinics.

\subsection{Development Trends of Acid-Base Neutralization-Reaction-Enabled Thermal} Ablation

Although strong acid and strong base are individually very destructive to tissues, the acid-base neutralization-reaction-enabled thermal ablation may be safe when appropriately administered (for example, designing injection needle with micro-reactor at its front end to control the residual acid or base in tissue after treatment), since the reaction of $\mathrm{HCl}$ and $\mathrm{NaOH}$ leads to friendly matters for human body (e.g., $\mathrm{NaCl}$ and $\mathrm{H}_{2} \mathrm{O}$ ). In fact, both acid and base solution have been used separately for chemical ablation in oncology clinics $[30,31]$. The acid-base thermal ablation method may be 


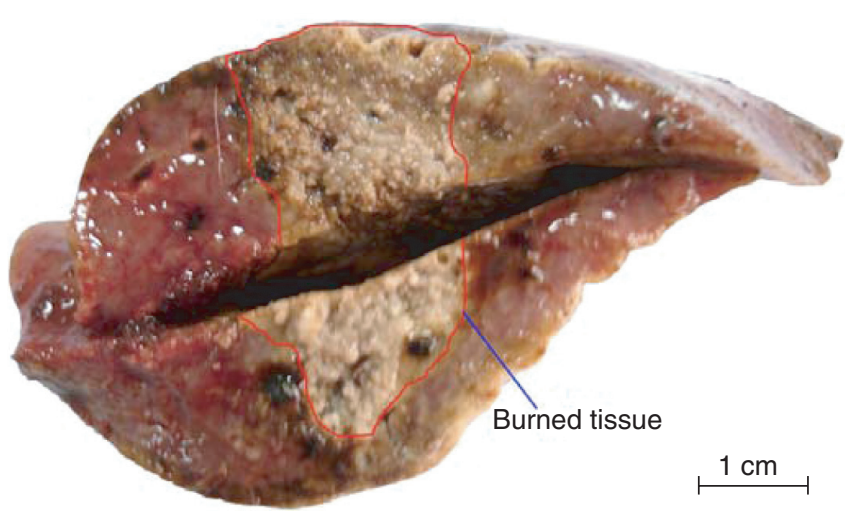

Figure 5. Profile of the burned area in rabbit liver tissue in an in vivo experiment, in which the reactants are $2 \mathrm{~g}$ of $37 \% \mathrm{w} / \mathrm{w} \mathrm{HCl}$ and $2 \mathrm{~g}$ of $40 \% \mathrm{w} / \mathrm{w}$ $\mathrm{NaOH}$, respectively [22]. Reproduced with permission.

safe for possible use in human body, but this needs to be verified through clinical studies. In addition, combined thermal and chemical ablation can be performed by controlling the dosage of acid and/or base.

Minimally invasive treatment has become a popular trend in oncology clinics. For the acid-base neutralization-reaction-enabled thermal ablation, the mechanical trauma caused by insertion of medical syringe is much smaller than most current percutaneous minimally invasive hyperthermia surgeries in which typical diameters of the inserted probes are from $2 \mathrm{~mm}$ to $5 \mathrm{~mm}$ or even larger. For tumors of irregular shapes, a conformal treatment can be administered by injecting reactants into multiple regions under the guidance of a medical imaging system such as ultrasound, MRI or X-CT. Due to its localized feature, the present method is beneficial in increasing tumor-killing while decreasing thermal injury to healthy tissues. Moreover, it is expected that such tumor treatment can possibly be performed on an outpatient basis in the future. Of course, many issues in mechanism, dosiology, safety and device development need to be investigated before clinical applications of the new method.

\section{ALKALI-METAL-ENABLED THERMAL/CHEMICAL ABLATION}

\subsection{Basic Principle}

Different from the acid-base neutralization-reaction-enabled thermal ablation, the alkali metal method uses the exothermic chemical reaction between ingredient in tissue (water) and alkali metal ( $\mathrm{Na}, \mathrm{K}$, or $\mathrm{NaK})$ [23]. After injection or transplantation of only an extremely small amount of such metals into the target tissue, a significant temperature increase or even combustion at the target site can occur, which results in thermal ablation of the tumor. The heat generation rate of such reaction is very high. For example, mixing alkali metal of sodium with a matched amount of water would release $281.778 \mathrm{~kJ} / \mathrm{mol}$ of heat, as shown by Equation 1. Besides, an immediate product of the 
reaction, $\mathrm{NaOH}$, further contributes to the heating if dissolved in water, and further raises the temperature of the targeted tissue.

$$
2 \mathrm{Na}+2 \mathrm{H}_{2} \mathrm{O}=2 \mathrm{NaOH}+\mathrm{H}_{2} \uparrow+281.778 \mathrm{KJ} / \mathrm{mol}
$$

As illustrated in Figure 6, the above event has multi-mode therapeutic effects. Extraction of water from cells due to the hygroscopic nature of alkalis may cause damage to the tissue [32]. Alkalis also dissolve proteins of the tissues to form alkaline proteinate which is soluble and contains hydroxyl ions. These ions cause further chemical reaction and magnify injury to the tissue [33]. One merit of the present method is that the remaining reactant such as $\mathrm{Na}^{+}$is friendly and absorbable by the living tissues, since it is a basic element of the physiological fluid. Therefore, after the thermal ablation therapy, the alkalis are expected not to cause any significant adverse effect when appropriately administered. However, this is subject to verification through further studies.

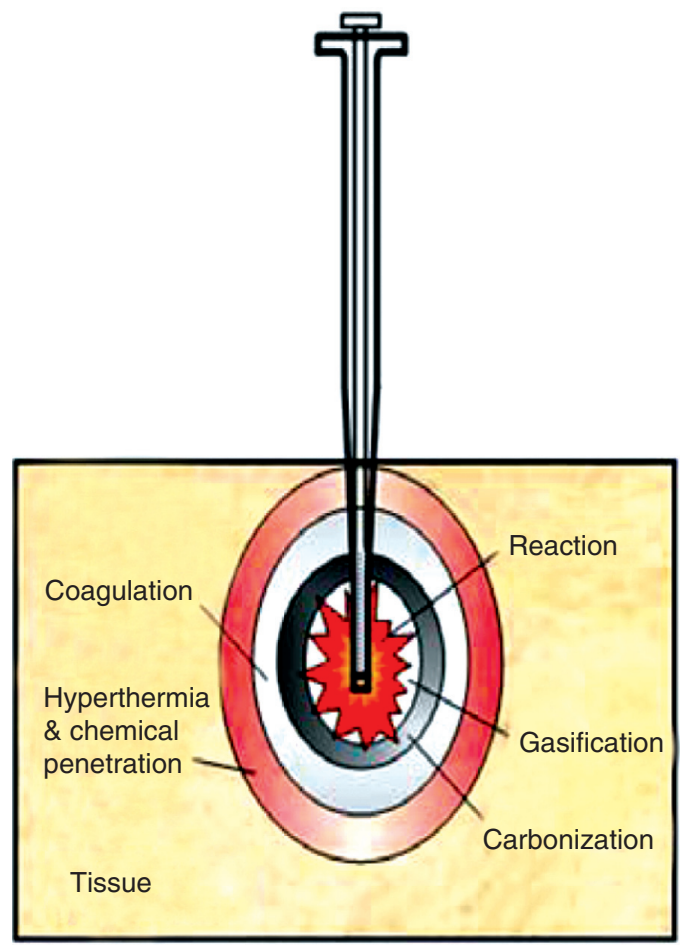

Figure 6. Thermal and chemical effects on the target tissue due to exothermic chemical reaction between alkali metal and the water in the biological tissue [23]. Reproduced with permission. 


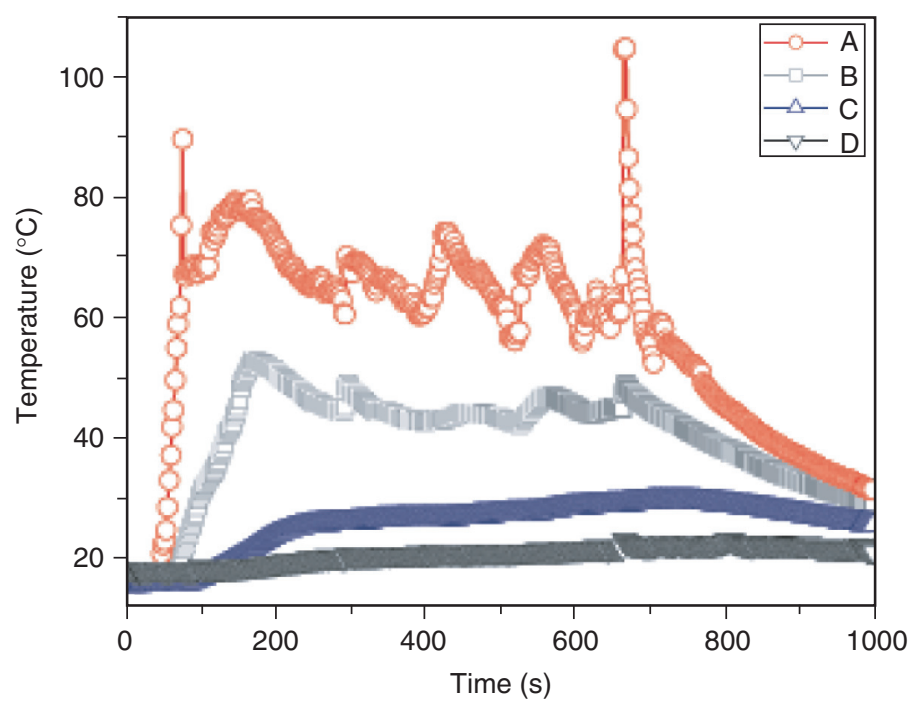

Figure 7. Tissue temperature variation during reaction process [23]. Reproduced with permission.

Figure 7 shows the temperature variation of an in vitro test of fresh beef using heating generated by alkali metal, in which $0.3 \mathrm{~g}$ of sodium was introduced into the beef. A temperature increase of about $90^{\circ} \mathrm{C}$ was recorded at site $\mathrm{A}$ which is at the center of the reaction region. The highest temperature level during the reaction can be quickly elevated to $90^{\circ} \mathrm{C}$ and then kept at above $60^{\circ} \mathrm{C}$, far higher than that required to thermally kill tumor tissue. At point $\mathrm{B}$, the temperature is still kept above $40^{\circ} \mathrm{C}$ during the reaction process. At points $\mathrm{C}$ and $\mathrm{D}$, temperature elevation is however not significant. Inspection of the target tissues showed that, a nearly round area with radius of $2.5 \mathrm{~cm}$ had been burned. All these results were achieved by injecting only a small amount of sodium into the target site.

\subsection{Anti-tumor Effect of Alkali-Metal-Enabled Thermal/Chemical Ablation}

To disclose the fundamental mechanisms of tumor treatment by the alkali-metalenabled thermal ablation, Rao et al. conducted an experiment using EMT6 tumorbearing animal model [24]. Eight mice with tumors ranging from 1.0 to $1.5 \mathrm{~cm}$ were randomized into four groups. Two mice in the control group were given no therapy. In the second group, two mice received intratumoral injection of $1.5 \mathrm{ml}$ of $\mathrm{NaOH}$ solution $\left(1 \mathrm{~mol} / \mathrm{L},{ }_{\mathrm{P}} \mathrm{H}=14\right)$ at a rate of about $0.03 \mathrm{ml} / \mathrm{s}$ into the center of the tumor. In the third group, another two mice underwent sodium treatment, with $0.03 \pm 0.005 \mathrm{~g}$ of encapsulated sodium inserted into the tumor center along the horizontal direction. In the fourth group, hyperthermia was induced by electrical heating using a needle of $2.5 \mathrm{~mm}$ diameter with the same thermal dosage as that in sodium treatment group (the third group). Tumor dimensions in each group were measured daily after the treatment, and the tumor volume was determined according to Carlsson formula [34]: 


$$
V=\frac{1}{2} a \times b^{2}
$$

where $a$ is the longest diameter $(\mathrm{mm})$ and $b$ is the shortest diameter $(\mathrm{mm})$. Tumor tissues at treatment site of 4 mice, one from each of the 4 groups, were resected and histologically examined by light microscopy immediately after treatment. Tumors were cut into $5 \mu \mathrm{m}$ frozen sections and prepared for histological assessment with hematoxylin and eosin staining.

Tumor volume for each group was recorded daily after the treatment, and the results are exhibited in Figure 8. Strong necrosis of tumor occurred in sodium treatment group. No significant necrosis occurred in electric heating group. On the sixth day and the tenth day, the tumor disappeared in the sodium group. Therefore, the results suggest that the chemical effect of the sodium treatment is more important than the thermal ablation effect. Figure 9 shows the histological images for the above four groups, respectively. Untreated tumors showed infiltrating growth trend in the control group, as shown in Figure 9a. There is a partial destruction area in the group treated with $\mathrm{NaOH}$ solution injection, with the grey line indicating the region of necrotic tumor cells, as shown in Figure $9 \mathrm{~b}$. In the hyperthermia group, tumors surrounding the heating site showed no evidence of cell death, as shown in Figure 9c. In the sodium-treated group, the tumor cell structure completely disappeared and its nucleus was dissolved around the injection zone, as shown in Figure 9d. In summary, the alkali-metal-enabled thermal ablation has a better inhibitory effect on tumor growth compared to the thermal or chemical

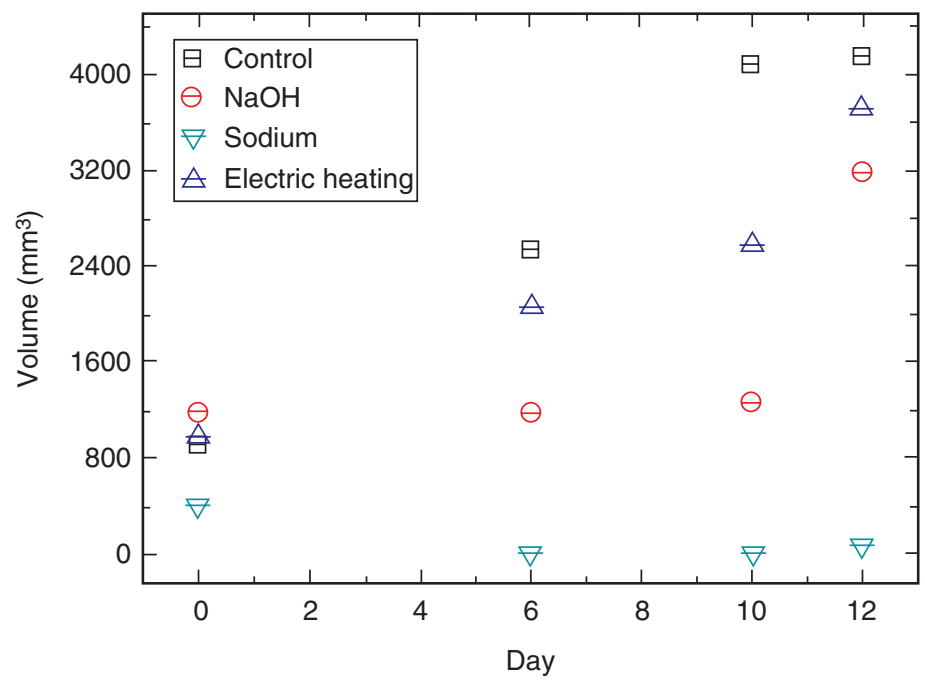

Figure 8. Tumor volumes change in four groups during the 12 days after treatment. Mice in control group, $\mathrm{NaOH}$ group, Sodium group and elactric heating group underwent no treatment, intratumoral injection of $\mathrm{NaOH}$ solution, Sodium capsule therapy and heating needle therapy, respectively [24]. Reproduced with permission. 
(a)

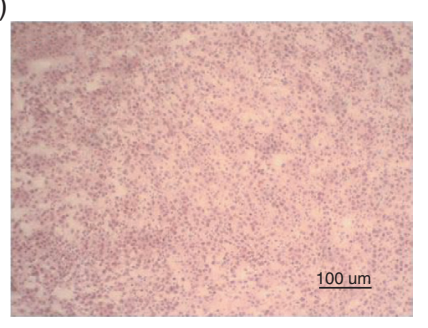

(c)

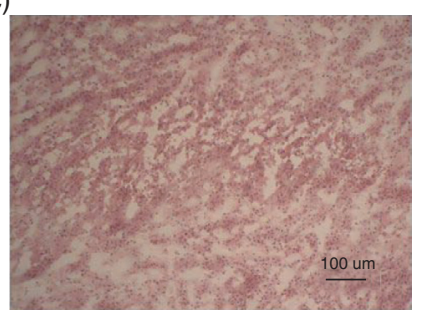

(b)

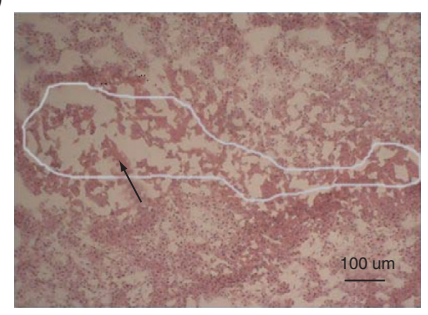

(d)

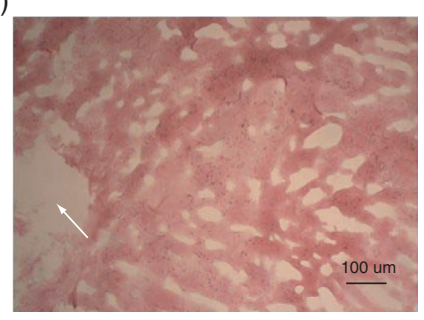

Figure 9. Hematoxylin/eosin staining of EMT6 tumor immediately after treatment for the four groups. (a) The control group showed infiltrating growth trend. (b) The $\mathrm{NaOH}$ group showed necrotic tumor cells (marked by black arrow) and a region of necrotic tumor cells indicated by the grey line. (c) The electric heating group showed no significant change. (d) The sodium group showed cell necrosis around the injection zone indicated by the white arrow [24]. Reproduced with permission.

treatment alone. Histological examination revealed complete destruction of tumor tissues, suggesting that sodium could be employed as a therapeutic agent to destroy malignant tumors.

\subsection{Development Trends of Alkali Metal Enabled Thermal/Chemical Ablation}

The alkali-metal-based ablation provides both thermal and chemical effects during treatment and could result in significant tumor necrosis. The heat released from the chemical reaction between alkali metal and water provides thermal ablation treatment that could be confined within the target tissues. Such heating performance, almost impossible by many advanced thermal ablation applicators, may be developed into an effective and minimally invasive tumor treatment through injecting only a small amount of alkali metal. However, safety should always be the first priority for patients and clinicians when performing such treatment. While reaction between bare alkali metal and tissue is rather strong and rapid, encapsulated alkali metal may provide a heat release process that can be more easily controlled, safer, and more feasible for clinical application.

Although previous results indicated that the alkali-metal-enabled thermal ablation can produce a complete necrosis around the tissues where the reactant is introduced, incomplete destruction of the malignant cells is possible due to the fact that tumor shape 
is usually irregular. Therefore, appropriate dosage and conformal treatment is important in minimizing damage to normal tissue while maximizing tumor cell necrosis. This can be conveniently achieved by injecting reactants of alkali metal fluid such as $\mathrm{NaK}$ alloy into multiple regions under the guidance of a medical imaging system [35]. In addition, some commonly used temperature sensors such as thermocouples or infrared thermometer can be employed to monitor in situ the temperature hike due to heat generation by reaction between alkali metal and water in tissue.

In summary, localized ablation using alkali metal is potentially an effective, safe and low cost way to treat malignant tumors. However, using alkali metal as chemothermal ablation agent is still at its incubating stage. Research efforts are needed both in device improvement and thermal dosage investigation in the near future.

\section{DISCUSSION}

Although thermal ablation to kill tumor with high temperature is playing an increasingly important role in oncological clinics, hyperthermia in conjunction with other therapy usually can produce superior results compared with that of a single treatment. In many existing studies, better outcomes have been achieved with combinations of hyperthermia and radiotherapy [36], chemotherapy [37] or radiochemotherapy [2]. In clinical practice, hyperthermia and chemical ablation alone have been widely adopted. Attempts were also made on combining these two therapies for a better output. The exothermic-chemical-reaction-based ablation therapy could result in more significant tumor necrosis through both thermal and chemical effects. Previous results on the chemothermal therapy have demonstrated better effectiveness in tumor cell necrosis than thermal or chemical ablation alone [23, 24, 38-40]. The fact that the heated tumor cells in alkaline environment can generate significant damage [24] also proves the chemothermal effect is not just a simple superposition of thermal effect and chemical effect; i.e., it is a synergistic effect. The underlying mechanism of the chemothermal ablation needs to be investigated. For the new chemothermal method, the emphasis still lies in that no additional surgical equipment but injection of only an extremely small amount of matched reactants is needed to achieve effective destruction of tumor.

Theoretically speaking, the kinetics of the destruction process of living tumor tissue can be described as the first-order chemical reaction process dependent on activation energy, temperature and frequency factor [41]. A generalized expression for the damage rate is given by the Arrhenius formulation:

$$
\frac{d \Omega}{d t}=K=P \cdot \exp \left(-\frac{E_{a}}{R T}\right)
$$

where $\Omega$ represents damage, $t$ is time, $K$ is the damage rate, $P$ is a constant corresponding to chemical reaction frequency $(1 / \mathrm{s}), E_{a}$ is the activation energy $(\mathrm{J} / \mathrm{mol})$, $R$ is universal gas constant $(\mathrm{J} /(\mathrm{mol} \cdot \mathrm{K}))$, and $T$ is the absolute temperature $(\mathrm{K}) . P$ and $E_{a}$ are normally determined by curve-fitting the experimental data. Since chemothermal ablation combines both effects of hyperthermia and chemical ablation, the activation energy for chemothermal ablation should be expressed as: 


$$
E_{a}=E_{t}+E_{c}
$$

where $E_{t}$ is activation energy reflecting thermal effect, $E_{c}$ is activation energy characterizing the chemical contribution. In eqn. $3, P$ increases with $E_{a}$ and is exponentially dependent on the entropy of activation [42]. As a result, the injury rate still increases with $E_{a}$, although eqn. 3 seemingly indicates that the injury rate decreases with $E_{a}$. The above equations explain why the anti-tumor effect of chemothermal ablation is not a linear superposition of thermal and chemical effects, but a synergy with a combined effect greater than each of the two.

The exothermic chemical reaction between acid and base (or between alkali metal and water) suggests a viable protocol for the combined thermal ablation and chemical therapy. Using the heat released from the exothermic chemical reaction, safe thermal ablation may be achieved and may be confined within only the target. In addition, the alkaline environment further induce a swelling of tissue with liquefied and coagulation necrosis, and hence cell death. Such performance suggests an effective and minimally invasive thermal/chemical ablation for tumor treatment. The reactants used in the chemothermal ablation during injection are at room temperature which is safe for the tissue surrounding the injection needle. Therefore unnecessary burning injury to the healthy tissues can be avoided. The chemothermal method also allows therapeutic monitoring and guidance. Since the injected amount of the matched reactants is rather small and with no anti-electromagnetic effect, the chemothermal ablation is compatible with most routinely used clinical image devices such as MRI, ultrasound and X-CT. Injection of chemical substances may also possibly be adopted as an imaging enhancer. In future clinics, to detect in situ the heat dosage during chemothermal therapy, some common temperature sensors such as thermal couples can also be adopted for monitoring and administrating the ablation procedure.

\section{CONCLUSIONS AND FUTURE DIRECTION}

This review has highlighted some of the latest innovations of a new type of tumor hyperthermia - chemothermal therapy. Our previous works suggested that chemothermal therapy has a clinical potential to contribute to low cost, safe and effective ablation of tumors, as it can provide localized heating through exothermic chemical reactions, possibly even on an outpatient basis. The thermal dosage of chemothermal therapy (including acid-base neutralization-reaction-enabled thermal ablation, alkali-metal-enabled thermal ablation, and possible other candidates) is controllable by adjusting the amount of reactant(s). The temperature achieved by the chemothermal procedures can be monitored by common temperature sensors such as thermocouples. Different from the conventional hyperthermia strategies, the new method can combine thermal and chemical ablation by controlling the dosage of reactant. In addition, new modality of hybrid cryosurgery and hyperthermia can be developed by combining chemothermal method and any cryosurgical applicator. Moreover, it is worth exploring chemothermal procedures for treating cardiac and vascular diseases. 
It should be emphasized that the newly developed chemothemal therapy is overall still at its stage of incubation and proof of clinical concept. Much research is needed (such as animal and clinical tests for safety and efficacy, development of the corresponding medical devices, and thermal dosage investigation) before possible clinical implementation.

\section{ACKNOWLEDGEMENTS}

Parts of the studies reviewed in this work were supported by the National Natural Science Foundation of China under Grant Nos. 51076161 and 81071255, the Specialized Research Fund for the Doctoral Program of Higher Education.

\section{CONFLICT OF INTEREST}

The authors indicate no potential conflicts of interest.

\section{REFERENCES}

[1] Liu J, Deng ZS. Physics of Tumor Hyperthermia (in Chinese), Science Press, Beijing, 2008.

[2] Falk MH, Issels RD. Hyperthermia in oncology. International Journal of Hyperthermia, 2001, 17:1-18.

[3] Samaras GM, Cheung AY. Microwave hyperthermia for cancer therapy. CRC Critical Reviews in Bioengineering, 1981, 5:123-184.

[4] Dong BW, Zhang J, Liang P, Yu XL, Su L, Yu DJ, Ji XL, Yu G. Sequential pathological and immunologic analysis of percutaneous microwave coagulation therapy of hepatocellular carcinoma. International Journal of Hyperthermia, 2003, 19:119-33.

[5] Liang P, Dong B, Yu X, Yu DJ, Cheng ZG, Su L, Peng JS, Nan Q, Wang HJ. Computer-aided dynamic simulation of microwave-induced thermal distribution in coagulation of liver cancer. IEEE Transactions on Biomedical Engineering, 2001, 48: 821-9.

[6] Madersbacher S, Pedevilla M, Vingers L, Susani M, Marberger M. Effect of high-intensity focused ultrasound on human prostate cancer in vivo. Cancer Research, 1995, 55:3346-3351.

[7] Cordeiro ER, Cathelineau X, Thüroff S, Marberger M, Crouzet S, Rosette J. High-intensity focused ultrasound (HIFU) for definitive treatment of prostate cancer. BJU International, 2012, DOI: 10.1111/j.1464-410X.2012.11262.x

[8] Wood BJ, Ramkaransingh JR, Fojo T, Walther MM, Libutti SK. Percutaneous tumor ablation with radiofrequency. Cancer, 2002, 94:443-451.

[9] Rossi S, Garbagnati F, Lencioni R, Allgaier HP, Marchianó A, Fornari F, Quaretti P, Tolla GD, Ambrosi C, Mazzaferro V, Blum HE, Bartolozzi C. Percutaneous radio-frequency thermal ablation of nonresectable hepatocellular carcinoma after occlusion of tumor blood supply. Radiology, 2000, 217:119-126.

[10] Jordan A, Wust P, Fahling H, John W, Hinz A, Felix R. Inductive heating of ferrimagnetic particles and magnetic fluids - physical evaluation of their potential for hyperthermia. International Journal of Hyperthermia, 1993, 9:51-68.

[11] Jordan A, Scholz R, Maier-Hauff K, van Landeghem FK, Waldoefner N, Teichgraeber U, Pinkernelle J, Bruhn H, Neumann F, Thiesen B, von Deimling A, Felix R. The effect of thermotherapy using magnetic nanoparticles on rat malignant glioma. Journal of Neuro-Oncology, 2006, 78:7-14.

[12] Moroz P, Jones SK, Gray BN. The effect of tumour size on ferromagnetic embolization hyperthermia in a rabbit liver tumour model. International Journal of Hyperthermia, 2002, 18:129-140.

[13] Haase C, Nowak U. Role of dipole-dipole interactions for hyperthermia heating of magnetic nanoparticle ensembles. Physical Review B, 2012, 85:045435.

[14] Dai LJ, Hua GR, Qian AP, Qian ZY. Investigation on local optical parameters of liver tumors in laserinduced thermotherapy. Applied Mechanics and Materials, 2012, 121-126:3998-4002. 
[15] Vogl TJ, Straub R, Zangos S, Mack MG, Eichler K. MR-guided laser-induced thermotherapy (LITT) of liver tumours: experimental and clinical data. International Journal of Hyperthermia, 2004, 20:713-724.

[16] Lindner U, Trachtenberg J, Lawrentschuk N. Focal therapy in prostate cancer: modalities, findings and future considerations. Nature Reviews Urology, 2010, 7:562-571.

[17] Honda N, Guo Q, Uchida H, Ohishi H, Hiasa Y. Percutaneous hot saline injection therapy for hepatic tumors: an alternative to percutaneous ethanol injection therapy. Radiology, 1994, 190:53-57.

[18] Roemer RB. Engineering aspects of hyperthermia therapy. Annual Review of Biomedical Engineering, 1999, 1:347-376.

[19] Soares PI, Ferreira IM, Igreja RA, Novo CM, Borges JP. Application of hyperthermia for cancer treatment: recent patents review. Recent Patents on Anti-cancer Drug Discovery, 2012, 7:64-73.

[20] Liu J, Deng ZS, Rao W. Way to ultra low cost tumor hyperthermia treatment: Targeted high intensity thermochemical ablation therapy (in Chinese). Science and Technology Review, 2008, 26(2):78-84.

[21] Deng ZS, Liu J, Zhou YX. Tumor hyperthermia method based on exothermic chemical reaction. China Patent No. 200610083646.6, 2006.

[22] Deng ZS, Liu J. Minimally invasive thermotherapy method for tumor treatment based on an exothermic chemical reaction. Minimally Invasive Therapy and Allied Technologies, 2007, 16:341346.

[23] Rao W, Liu J. Tumor thermal ablation therapy using alkali metals as powerful self heating seeds. Minimally Invasive Therapy and Allied Technologies, 2008, 17(1):43-49.

[24] Rao W, Liu J, Zhou YX, Yang Y, Zhang H. Anti-tumor effect of sodium-induced thermochemical ablation therapy. International Journal of Hyperthermia, 2008, 24:675-681.

[25] Misselt AJ, Edelman TL, Choi JH, Bischof JC, Cressman EN. A hydrophobic gel phantom for study of thermochemical ablation: initial results using a weak acid and weak base. Journal of Vascular and Interventional Radiology, 2009, 20:1352-1358.

[26] Cressman EN, Tseng HJ, Talaie R, Henderson BM. A new heat source for thermochemical ablation based on redox chemistry: initial studies using permanganate. International Journal of Hyperthermia, 2010, 26:327-337.

[27] Freeman LA, Anwer B, Brady RP, Smith BC, Edelman TL, Misselt AJ, Cressman EN. In vitro thermal profile suitability assessment of acids and bases for thermochemical ablation: underlying principles. Journal of Vascular and Interventional Radiology, 2010, 21:381-385.

[28] Farnam JL, Smith BC, Johnson BR, Estrada R, Edelman TL, Farah R, Cressman EN. Thermochemical ablation in an ex-vivo porcine liver model using acetic acid and sodium hydroxide: proof of concept. Journal of Vascular and Interventional Radiology, 2010, 21:1573-1578.

[29] Dean JA. Lange's Chemistry Handbook. 15th ed., McGraw-Hill Professional, New York, 1998.

[30] Ohnishi K, Ohyama N, Ito S, Fujiwara K. Small hepatocellular carcinoma: treatment with US-guided intratumoral injection of acetic acid. Radiology, 1994, 193:747-752.

[31] Liu LM, Zhang YH, Xu GY. A study of the feasibility of sodium hydroxide solution as tumor ablation agent. Chinese Journal of Ultrasound Medicine, 2000, 16:325-327.

[32] Acikel C, Ulkur E, Guler MM. Prolonged intermittent hydrotherapy and early tangential excision in the treatment of an extensive strong alkali burn. Burns, 2001, 27:293-296.

[33] Mozingo DW, Smith AA, McManus WF, Pruitt BA, Mason AD. Chemical burns. Journal of Trauma, 1988, 28:642-647.

[34] Carlsson G, Gullberg B, Hafström L. Estimation of liver tumor volume using different formulas—an experimental study in rats. Journal of Cancer Research and Clinical Oncology, 1983, 105:20-23.

[35] Rao W, Liu J. Injectable liquid alkali alloy based tumor thermal ablation therapy. Minimally Invasive Therapy and Allied Technologies, 2009, 18:30-35. 
[36] Harima Y, Nagata K, Harima K, Ostapenko VV, Tanaka Y, Sawada S. A randomized clinical trial of radiation therapy versus thermoradiotherapy in stage IIIB cervical carcinoma. International Journal of Hyperthermia, 2001, 17:97-105.

[37] Haaga JR, Exner AA, Wang YD, Stowe NT, Tarcha PJ. Combined tumor therapy by using radiofrequency ablation and 5-FU-laden polymer implants: Evaluation in rats and rabbits. Radiology, 2006, 238:911-918.

[38] Geeslin MG, Cressman EN. Thermochemical ablation: a device for a novel interventional concept. ASME Journal of Medical Devices, 2012, 6:015001.

[39] Cressman EN, Shenoi MM, Edelman TL, Geeslin MG, Hennings LJ, Zhang Y, Iaizzo PA, Bischof JC. In vivo comparison of simultaneous versus sequential injection technique for thermochemical ablation in a porcine model. International Journal of Hyperthermia, 2012, 28:105-112.

[40] Cressman EN, Geeslin MG, Shenoi MM, Hennings LJ, Zhang Y, Iaizzo PA, Bischof JC. Concentration and volume effects in thermochemical ablation in vivo: Results in a porcine model. International Journal of Hyperthermia, 2012, 28:113-121.

[41] Deckers R, Debeissat C, Fortin PY, Moonen C, Couillaud F. Arrhenius analysis of the relationship between hyperthermia and Hsp70 promoter activation: A comparison between ex vivo and in vivo data. International Journal of Hyperthermia, 2012, 28:441-450.

[42] He X. Thermostability of biological systems: Fundamentals, challenges, and quantification. The Open Biomedical Engineering Journal, 2011, 5:47-73. 



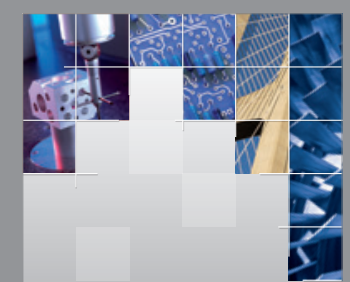

\section{Enfincering}
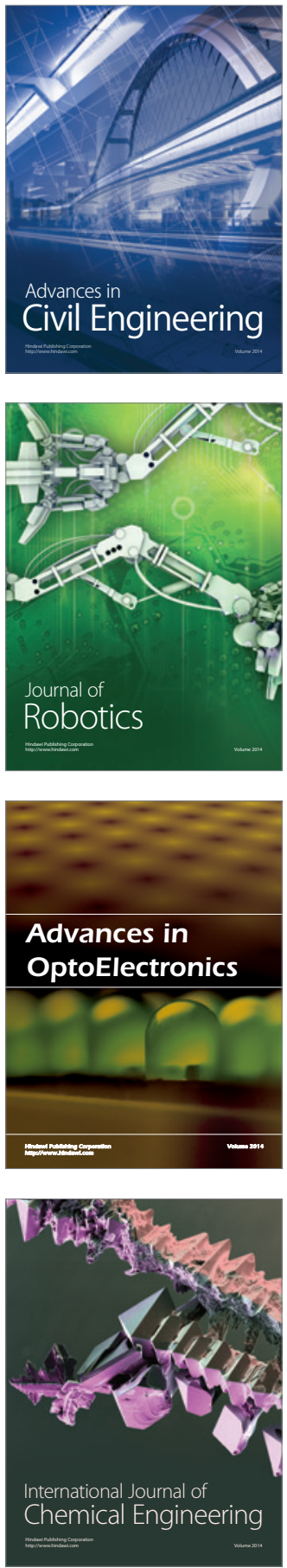

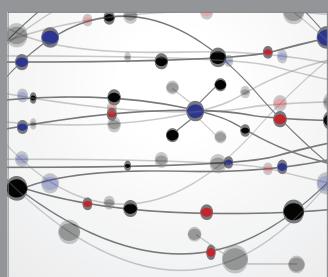

The Scientific World Journal

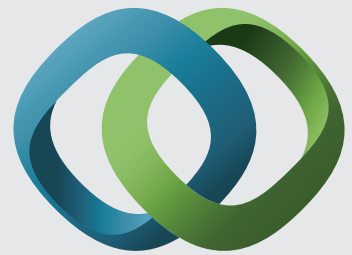

\section{Hindawi}

Submit your manuscripts at

http://www.hindawi.com
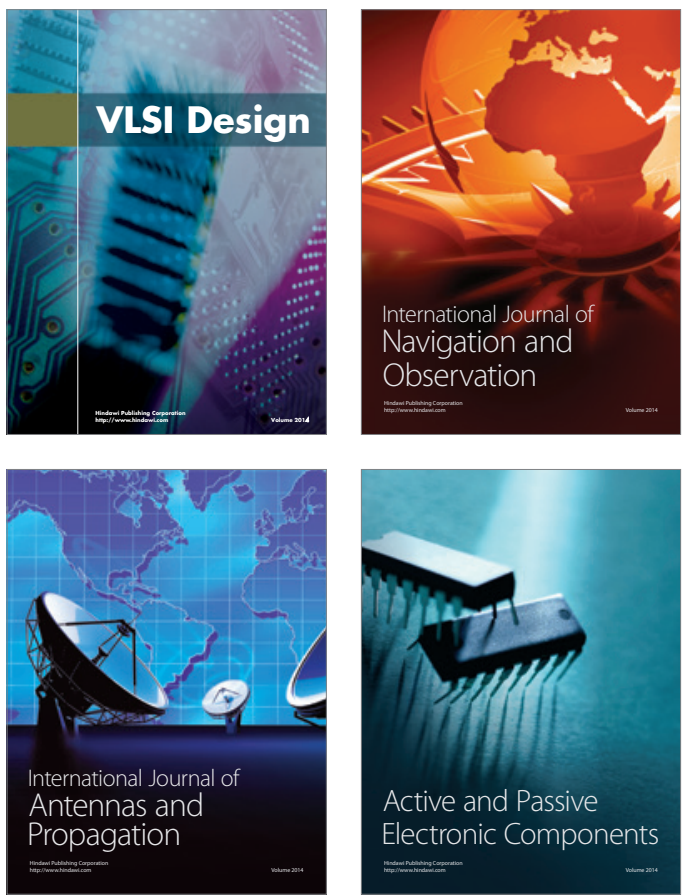
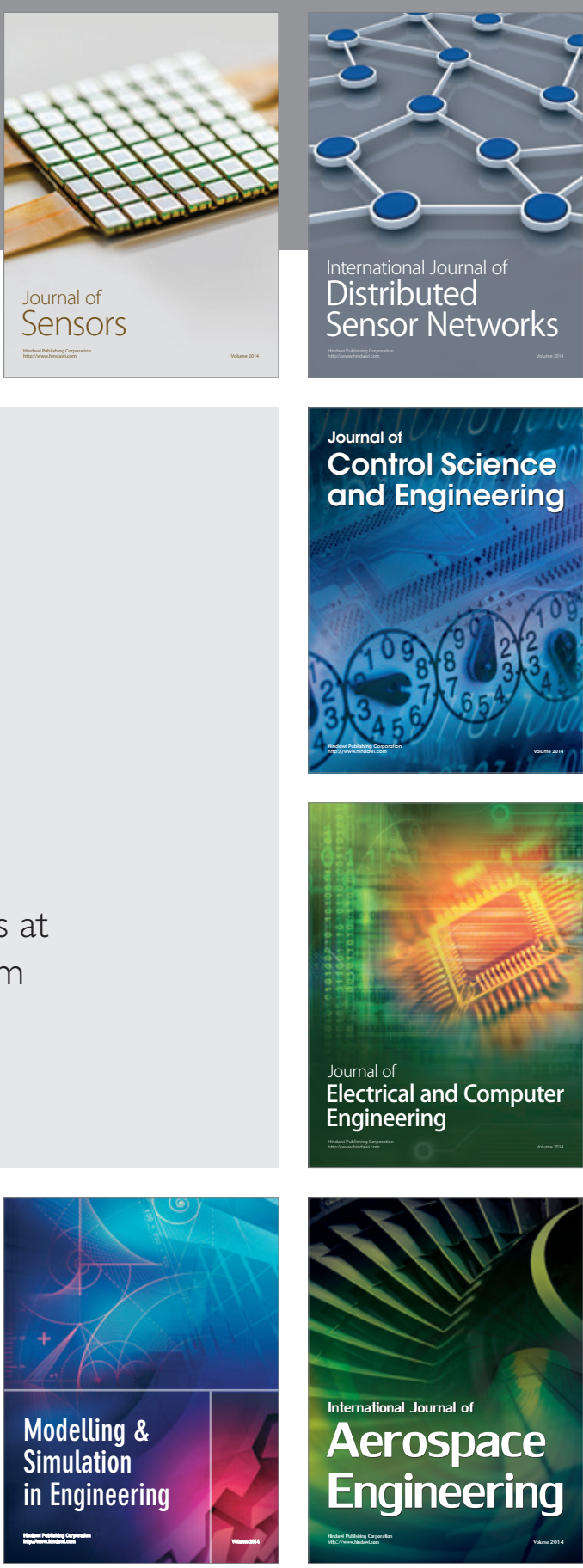

International Journal of

Distributed

Sensor Networks

Journal of

Control Science

and Engineering
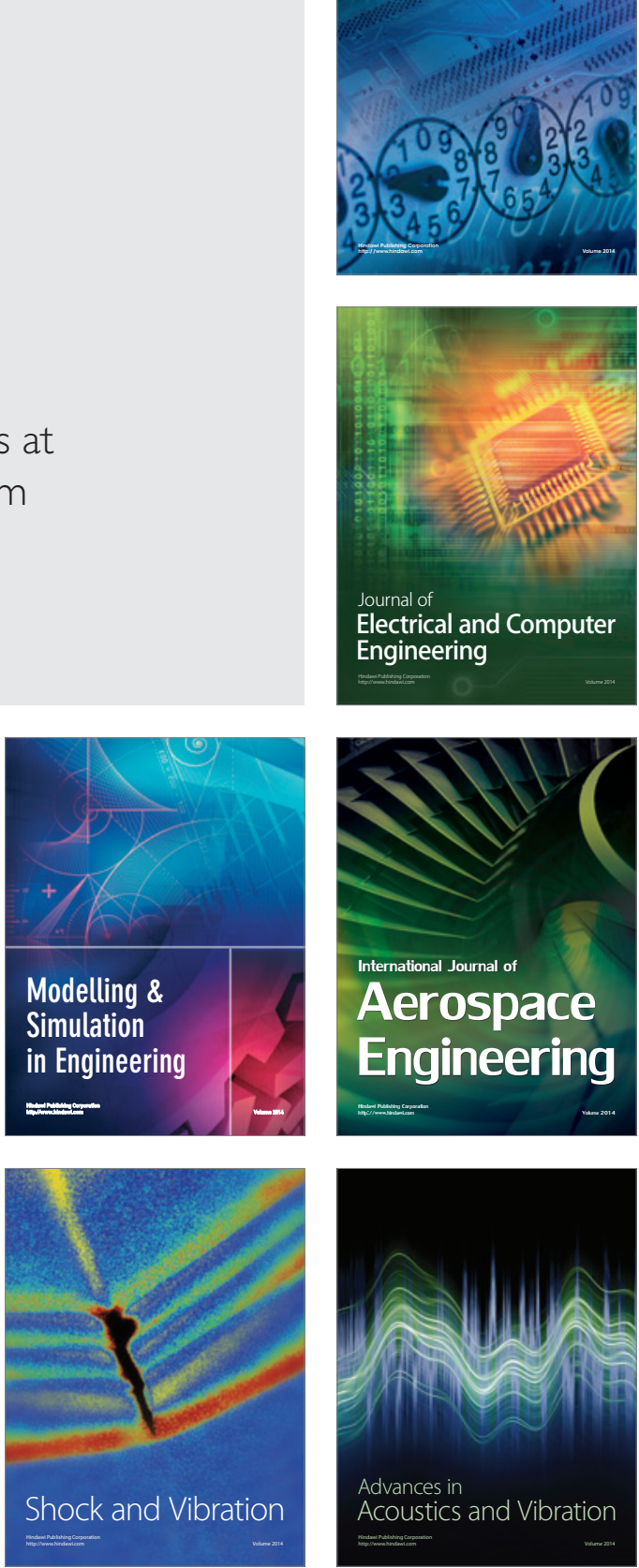